Thorax (1966), $21,325$.

\title{
Mediastinal emphysema: aetiology, diagnosis, and treatment
}

\author{
J. M. GRAY AND G ILLIAN C. HANSON \\ Fıom Whipps Cross Hospital, London E.11, and the Obstetric Unit, Forest Gate Hospital, London E.11
}

Mediastinal emphysema is a condition frequently omitted in the differential diagnosis of retrosternal chest pain ; it is generally benign but on occasions can be fatal. Little has been written about this condition, and, although rare, it has probably been misdiagnosed or has not been detected in the past.

\section{AETIOLOGICAL CLASSIFICATION}

1. Rupture of marginal alveoli into the pulmonary interstitial tissue and thence to the mediastinum

2. Mixed aetiological factors (The mode of production is not yet certain.)

(a) Spontaneous pneumomediastinum

(b) Trauma to the chest wall

3. Air entering the mediastinum from the deep fascial planes of the neck

4. Air entering the mediastinum from the retroperitoneal space

5. Perforation of the trachea, bronchus, or oesophagus into the mediastinum

\section{RUPTURE OF MARGINAL ALVEOLI INTO PULMONARY INTERSTITIAL TISSUE}

The mechanism of production of pulmonary interstitial emphysema of the lungs and its spread into the mediastinum has been described by Macklin and Macklin (1944). They emphasized that a pressure gradient must exist between the alveolus and the underlying connective tissue so that air can pass from the alveolus into the tissues.

Pneumomediastinum follows the development of pulmonary interstitial emphysema, since air tends to follow the path of least resistance and travels along the vascular sheaths to the hilus.

MIXED AETIOLOGICAL FACTORS

Spontaneous pneumomediastinum Macklin and
Macklin (1944) thought that this condition arose following rupture of marginal alveoli producing pulmonary interstitial emphysema and later pneumomediastinum. The cause of rupture is difficult to establish; but rupture probably does not occur unless one at least of the following is present: overinflation, relative increase of intrapulmonary pressure as compared with that on the chest wall, or decreased pulmonary circulation. Gordon (1936) and Kjaergaard (1933) maintained that ruptured blebs caused spontaneous pneumothorax despite the fact that in many of the cases which came to necropsy no ruptured pleural blebs were found. Scott (1957) stated that usually a pneumothorax is produced by rupture of an alveolus or bulla directly through the visceral pleura, and he postulated that air might enter the mediastinum by passing through the mediastinal pleura from the pleural cavity.

Trauma to the chest wall The mechanism of mediastinal emphysema following closed chest injuries is uncertain. The most likely cause is compression of one part of the chest followed by increased intra-alveolar pressure and rupture of some alveoli, with development of pulmonary interstitial emphysema followed by mediastinal emphysema.

AIR ENTERING MEDIASTINUM FROM DEEP FASCIAL PLANES OF THE NECK (Forbes, Salmon, and Herweg, 1947; Work, 1943) This may be the path followed during thyroidectomy or tonsillectomy and in deep wounds of the neck. However, in thyroidectomy and tonsillectomy a raised intraalveolar pressure secondary to outlet airway obstruction may be the primary factor, air entering the mediastinum from the lung interstices.

AIR ENTERING MEDIASTINUM FROM RETROPERITONEAL SPACE If air accumulates in the retroperitoneum it may travel alongside the aorta or the oesophagus 
into the mediastinum. This may follow perforation of the stomach or intestine or may occur after perirenal insufflation.

PERFORATION OF TRACHEA, BRONCHUS, OR OESOPHAGUS INTO MEDIASTINUM Disease or trauma occasionally causes rupture of the trachea or bronchi. Rupture of the trachea may be caused by a sudden increase of pressure in the tracheobronchial tree against a closed glottis or as a result of a shearing force (Rubin and Rubin, 1961). Rupture of the oesophagus may be due to a large number of causes, the site of the rupture depending on the aetiology. Penstrating wounds generally involve the cervical oesophagus and rarely produce mediastinal emphysema. Foreign bodies often lodge in the oesophagus at the level of the aortic arch crossing the left main bronchus.

Instrumentation remains the most frequent cause of oesophageal rupture (Anderson, 1952 ; Smith and Tanner, 1956). With a diseased oesophagus the most common site of rupture is at that level, but when not diseased the rupture generally takes place at the narrowest point in the oesophagus, namely at or just below the pharyngo-oesophageal orifice.

In spontaneous rupture the site involved is generally in the lower $8 \mathrm{~cm}$. of the oesophagus and is usually a vertical tear on the left posterolateral wall. Several explanations have been given for this site. First, the left side of the oesophagus is not supported by connective tissue, and, secondly, there appears to be an intrinsic weakness in the muscle wall at this point (Mackler, 1952). Increased intraluminal pressure within the oesophagus plays an important part in rupture of the lower third, and rupture may arise in labour (Kennard, 1950), during severe asthmatic seizures (Mitchell, Derbes, and Akenhead, 1955), during strenuous exercise (Griffith, 1932), and after vomiting secondary to increased intracranial pressure (Cushing, 1932; Fincher and Swanson, 1949). Many patients, however, give histories suggestive of previous gastro-intestinal disease, peptic ulcer, alcoholism, or gluttony. Barrett (1946) postulated that the cricopharyngeal sphincter in these patients fails to relax during the attempt at vomiting, and this, most often associated with a full stomach, raises the pressure within the oesophagus sufficiently high to produce rupture.

In most instances rupture of the oesophagus is probably the result of multiple factors, including incoordination, weakness of the oesophageal wall, and an increased pressure within the oesophagus.
CLINICAL FEATURES The most common symptom of mediastinal emphysema is pain, and the important clinical findings are subcutaneous emphysema predominantly in the neck, obliteration of the cardiac dullness, and peculiar sounds audible over the heart. In addition to these features there may be evidence of pneumothorax.

Mediastinal emphysema may arise when the patient is at rest and may be symptomless, or the patient may notice some swelling and/or crepitus in the neck. Subcutaneous emphysama may be the only clinical evidence for the presence of pneumomediastinum. Frequently the patient gives a history of coughing, vomiting, or sudden exertion. Pain is a frequent complaint; it is usually retrosternal and may radiate to the shoulders and down both arms; it is sharp and aggravated by inspiration and sometimes by swallowing. In addition, there is usually a feeling of oppression or constriction often associated with dyspnoea. Hamman (1945) attributed the retrosternal pain to distension and dissection of the mediastinal tissues with air.

Subcutaneous emphysema may be the only clinical evidence for the presence of pneumomediastinum and is due to air dissecting upwards between the fascial layers of the neck (Hollinshead, 1962). It is often detectable initially as a superficial crackling sound when a stethoscope is applied to the chest wall or neck. The apex beat may not be palpable, the cardiac dullness is diminished or absent, and the heart sounds are distant. Hamman's sign (Hamman, 1934, 1937) was at one time thought to be diagnostic of mediastinal emphysema (Hamman, 1937, 1939 ; Müller, 1888). The sign is present in $50 \%$ of cases (Sulavik, 1962) but may also be heard in leftsided pneumothorax (Scott, 1957), dilated lower oesophagus, bullous emphysema of the lingular segments, pneumoperitoneum with a high left diaphragm, and gastric dilatation (Sulavik, 1962). The sounds ara generally heard best along the left sternal edge, third to sixth intercostal space, they may vary in intensity and are intensified when the patient is sitting up or lying in the left lateral decubitus position. The sounds occur synchronously with the heart beat, are 'crunching' in character (Hamman, 1937), and are generally associated with systole but may be heard in diastole. If these sounds are heard in the presence of subcutaneous emphysema of the chest wall or neck, then mediastinal emphysema from whatever cause can be diagnosed. Pneumothorax is a frequent accompaniment. This is generally small and left-sided and occurs in one-third of cases of 
pneumomediastinum (Hamman, 1945). Tension pneumothorax may develop, and, since the lung is splinted by interstitial air, the size of the pneumothorax may have no relation to the intrapleural pressure (Nicholas, 1958).

Spontaneous mediastinal emphysema is generally a benign condition which subsides with no therapy, but occasionally increased mediastinal pressure develops, producing a state which can be fatal if not diagnosed promptly and treated. Macklin and Macklin (1944) described this severe type of spontaneous pneumomediastinum as 'malignant'. In 'malignant' mediastinum the patient is in a shocked state with dyspnoea, cyanosis, engorged (frequently non-pulsatile) neck veins, rapid low volume pulse, and low blood pressure. If not relieved the condition progresses to pulmonary oedema and circulatory failure.

In addition to the clinical features described above there may be accompanying findings related to the aetiology of the emphysema. These include chest wall injuries, lung collapse, pneumonia, pneumothorax, or fever associated with mediastinitis.

\section{DIAGNOSIS}

The most important single investigation to confirm the presence of pneumomediastinum is radiography of the chest. When Hamman's sign is negative, diagnosis can only be made with certainty by radiography. Air in the mediastinum may be seen in the postero-anterior film as a sharp, distinct line running parallel to the left, and sometimes to the right, border of the heart (Macklin, 1937). In the lateral film there is generally evidence of a substernal collection of air. Difficulty may arise in differentiating a ruptured oesophagus from pneumomediastinum due to other causes. In oesophageal rupture there is generally a known precipitating factor with a rapid onset of shock. Occasionally perforation is gradual, and in these cases there is usually a pleural effusion. In lower oesophageal rupture there is upper abdominal rigidity, and the signs closely mimic those of perforated gastric or duodenal ulcer. Pneumomediastinum of severe degree and oesophageal rupture may be difficult to differentiate from other causes, especially if the patient is seen early. A gastrographin swallow and chest radiograph should be performed, since it is imperative to operate immediately should the patient have a ruptured oesophagus.

Naclerio (1957) stated that the most valuable single diagnostic aid in spontaneous oesophageal rupture is the chest radiograph, and that if this is taken early it may show localized mediastinal emphysema in the lower part of the medistinum before the development of generalized mediastinal and/or subcutaneous emphysema, hydrothorax, or hydropneumothorax. In the neck, the radiograph may show on the lateral view the larynx and oesophagus pushed forward by a collection of air in the retrovisceral space (Barrett, 1952). Chamberlain and Byerly (1957) stated that free air under the diaphragm has never been seen as a result of oesophageal rupture.

The electrocardiogram in most cases of mediastinal emphysema is within normal limits (Aisner and Franco, 1949; Klein, 1947). About $25 \%$ of patients show non-specific changes such as $\mathrm{T}$ wave inversion, ST segment deviation, decreased voltage, and shifts in the electrical axis (Littmann, 1946). Myocardial infarction may be diagnosed if the mediastinal emphysema is missed.

Finally, on occasion bronchoscopy and/or oesophagoscopy are required to establish the cause for the mediastinal emphysema.

\section{PROGNOSIS}

The prognosis depends on the aetiology. In spontaneous cases, and in those associated with pneumothorax, the prognosis is good and the emphysema generally clears within one week. In pneumomediastinum of severe degree the condition may be fatal unless the air is released.

The pneumomediastinum may be a coincidental factor, the prognosis depending on the seriousness of the associated lesion and the rapidity with which it is treated.

\section{TREATMENT}

In oesophageal perforation and oesophageal or bronchial rupture treatment is directed toward these lesions, the mediastinal emphysema being merely a secondary factor.

In the other types of mediastinal emphysema, the emphysema generally resolves on conservative treatment. Should a large pneumothorax produce respiratory embarrassment or the lung be collapsed by more than $50 \%$ aspiration and underwater drainage or suction are necessary.

'Malignant' mediastinal emphysema requires urgent removal of air from the mediastinum. Collins (1948) advised the insertion of a needle parallel to the deep surface of the sternum through the third or fourth right intercostal space.

On occasions the air has to be released by 
multiple subcutaneous aspirations or incisions into the subcutaneous tissues where the air has accumulated. Cervical mediastinotomy may be necessary if aspiration of the mediastinum is successful but not sufficient, and on some occasions Hamman (1945) has recommended splitting of the sternum.

Fine, Hermanson, and Frehling (1938) found that subcutaneous and mediastinal emphysema could be relieved by breathing $95 \%$ oxygen. Nonsurgical pneumomediastinum would probably respond to hyperbaric oxygen therapy.

\section{CASE HISTORIES}

CASE 1 This girl aged 13 years was admitted in 1957 severely ill with a history of sore throat two days before admission and onset of rigors and breathlessness associated with retrosternal soreness on the night before admission. On admission her temperature was $105^{\circ} \mathrm{F}$. She was deeply cyanosed, drowsy, and toxic, and the respiratory rate was raised to $50 /$ minute, pulse rate $140 /$ minute, and blood pressure normal. There was clinical evidence of right lower lobe collapse, and a diagnosis of right lower lobe pneumonia was made. Nothing else abnormal was detected. She was treated with intramuscular soluble penicillin and streptomycin. The following day emphysema was noted in the neck and over the right anterior chest wall Hamman's sign was positive. Her general condition deteriorated and she died from staphylococcal toxaemia 36 hours after admission. Permission for necropsy was not granted.

Sputum, blood culture, and stools grew Staphylococcus pyogenes resistant to penicillin and sensitive to streptomycin. A chest radiograph (Figs $1 \mathrm{a}, \mathrm{b}$ and $2 \mathrm{a}$, b) the day after admission showed mediastinal emphysema, extensive subcutaneous emphysema of the neck and chest wall, and partial collapse of the right lower lobe.

The mediastinal emphysema in this patient most probably followed rupture of a marginal alveolus in the area of lung overinflation adjoining the right lower lobe atelectasis.

CASE 2 This patient aged 25 years was admitted to the obstetric unit on 27 December 1963 for elective caesarean section for disproportion. Nothing abnormal was detected on examination. The uterus was enlarged to the size of a 36 weeks pregnancy. On 28 December an uncomplicated caesarean section was performed. Thirty-six hours post-operatively she developed a stabbing right-sided chest pain which was aggravated by inspiration. On examination there was collapse of the right lower lobe. Surgical emphysema was absent, and Hamman's sign was negative.

Chest radiographs taken at this time showed collapse of the right middle and lower lobes. There was subcutaneous emphysema in the neck and air surrounding the mediastinal structures.

On 30 December the patient was bronchoscoped and pus was aspirated from the right middle and $\overline{\bar{c}}$ lower lobe bronchi. On 1 January surgical emphysema $\overparen{\Phi}$ was detected in the neck and over the anterior chest wall.

Her condition rapidly improved on a course of $\overrightarrow{0}$ oral penicillin, and at the time of discharge on 13. January her chest radiograph was normal.

It is most probable that the right middle lobe $\mathscr{\omega}$ collapse followed occlusion of the right middle lobe $\vec{\sim}$ bronchus with mucopus the day after operation, since $\underset{i}{\times}$ immediately post-operatively the patient was fit and the chest was clinically clear. The sudden lung collapse may have ruptured a marginal alveolus in the adjoining overexpanded lung. The mediastinal $G$ emphysema did not follow bronchoscopy, since the radiograph taken before this procedure showed air in the mediastinum. In this patient the pneumo- $c$ mediastinum caused no distress and subsided spon- $<$ taneously.

CASE 3 A man 28 years of age was admitted in March 1965. On the day before admission, while sitting in a chair, he developed severe retrosternal chest pain which radiated into both midzones anteriorly and to the left shoulder. The pain, $\frac{\circ}{\mathbb{Q}}$ described as a heavy weight, lasted 10 minutes and $\cong$ was associated with breathlessness. The pain then $\overrightarrow{\overrightarrow{0}}$ subsided, and he went home to bed. Later the same 3 evening he got out of bed and developed a transitory retrosternal chest pain with no radiation, again associated with breathlessness. He was seen by his general practitioner, who recorded the blood pressure at $80 / 55 \mathrm{~mm}$. Hg. The next morning he was more comfortable and had retrosternal chest pain only on: movement; but he still had a low blood pressure. No abnormality was detected in the lungs. He was admitted that morning with the possible diagnosis of $O$ myocardial infarction.

On admission there was no cyanosis, he was응 breathless on movement but comfortable at rest. Blood pressure was $120 / 80 \mathrm{~mm}$. Hg. The jugulo-o venous pressure was raised $3 \mathrm{~cm}$. and was nonpulsatile, the apex beat was not palpable, no area $N$ of cardiac dullness could be detected, the heart $N$ sounds were distant, and there was a soft 'creak' over the apex during mid-systole. There was palpable $\omega$ emphysema over the anterior chest wall and evidence $\bar{\sigma}$ of a left-sided pneumothorax. Chest radiographse showed a left pneumothorax with complete collapse $\frac{\mathbb{D}}{\mathbb{D}}$ of the left lung. Subcutaneous emphysema was $\stackrel{\infty}{+}$ visible above the clavicles, over the chest wall, and 7 surrounding the mediastinal structures. He was given ${ }_{0}^{-}$ a course of intramuscular penicillin, and on the day $\overrightarrow{\mathbb{D}}$

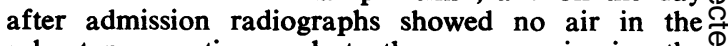
subcutaneous tissues but there was air in the $\stackrel{\mathbb{Q}}{2}$ mediastinum; the lung had not expanded. A tube was inserted into the pleural cavity and connected to an underwater drain; the lung expanded com-o 


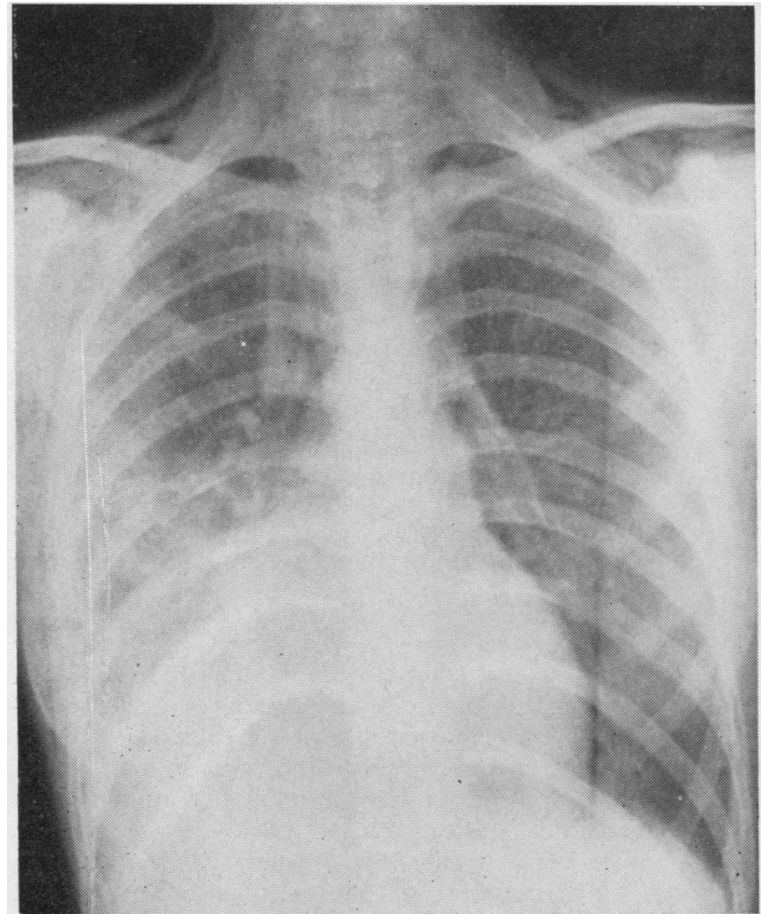

(a)

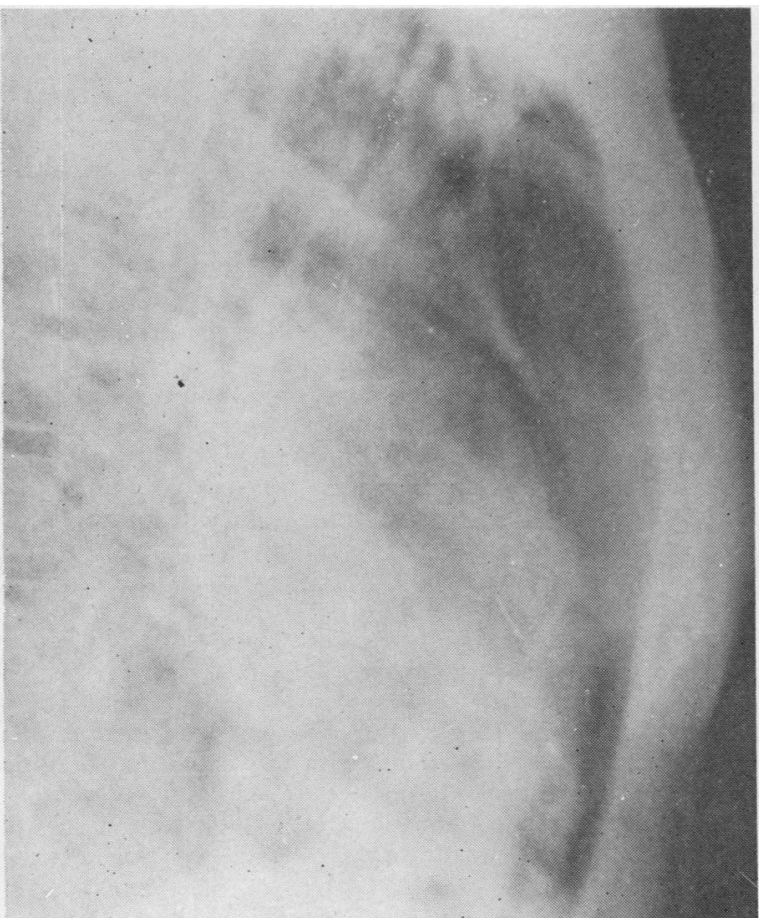

(a) (b)

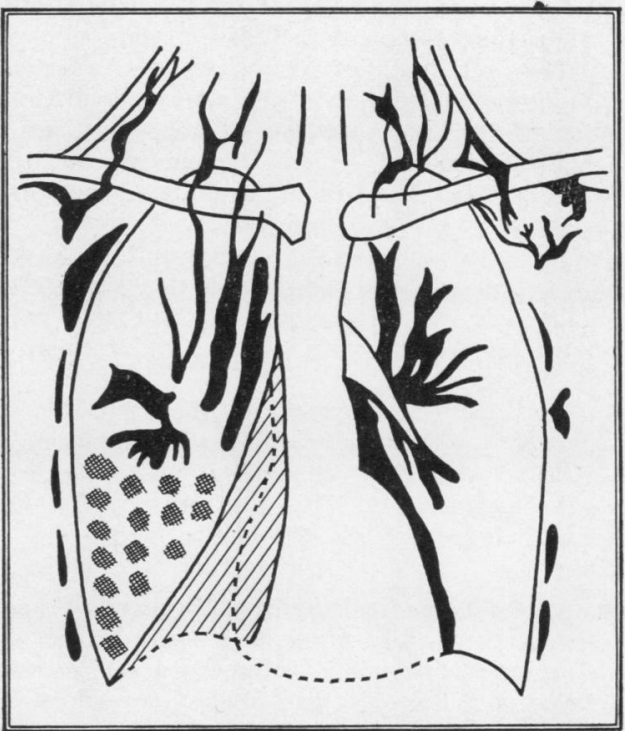

FIG. 1. (a) Postero-anterior view showing mediastinal emphysema, extensive surgical emphysema of the neck, and partial collapse of the right lower lobe. (b) Line diagram of (a) showing air in the subcutaneous tissues; air outlining the left border of the heart; and extensive interstitial emphysema of the lungs.

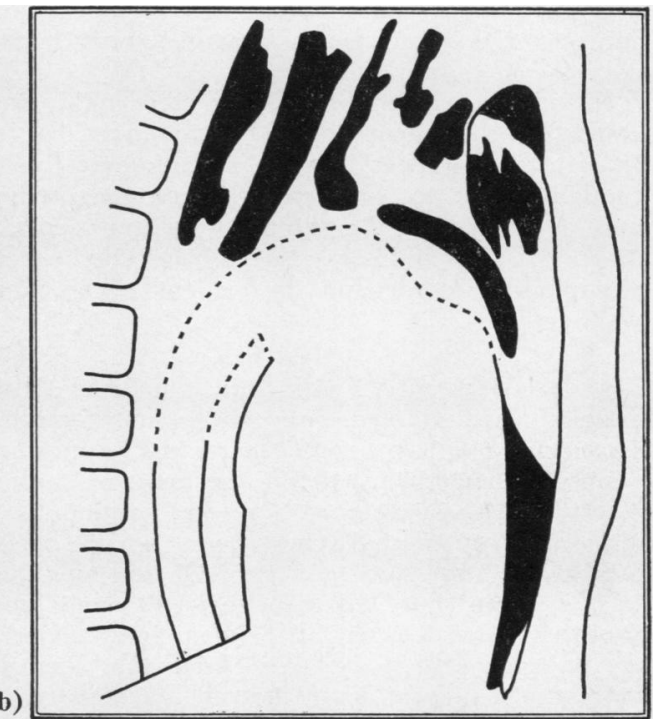

FIG. 2. (a) Chest radiograph, lateral view. (b) Line diagram of (a) showing air beneath the sternum and surrounding the anterior border of the heart. 
pletely over the next 24 hours. Chest radiographs taken four days after admission were normal.

The aetiology of pneumothorax associated with pneumomediastinum is still controversial. In this case the history is suggestive at the onset of pneumomediastinum of severe degree producing central retrosternal chest pain, dyspnoea, and low blood pressure. This was presumably followed by release of air into the pleural cavity and neck with relief of symptoms. On admission the retrosternal chest pain was no longer present, but the patient was breathless on exertion because of complete collapse of the left lung.

An electrocardiogram at the time of admission showed low voltage complexes throughout all leads with no axis shift, change in QRS complexes, or T wave abnormality. This was presumably due to the accumulation of air within the pericardial sac.

CASE 4 A medical student 22 years of age gave a history that while sitting in a train on the way to an examination he had experienced a retrosternal aching sensation; this was not severe enough to stop his taking the examination. The retrosternal discomfort continued throughout the day. That night, while reading in bed, he noted that his neck had swollen and crepitus was present on either side of the neck. On admission the only abnormalities detected were subcutaneous emphysema of the neck and a positive Hamman's sign.

Chest radiographs showed mediastinal emphysema and air in the subcutaneous tissues of the neck. Oesophagoscopy was normal. The mediastinal and subcutaneous emphysema spontaneously subsided over the next four days.

In this patient the symptoms were mild, and no cause for the pneumomediastinum could be found. In spite of the clear lung fields radiologically it was thought wise to perform an oesophagoscopy to exclude oesophageal rupture. In retrospect, this diagnosis was unlikely, there being no suggestive precipitating factor and the patient being clinically well.

CASE 5 A patient 22 years old, who was 12 weeks pregnant, had suffered from nausea and vomiting for six weeks. She had vomited early in the morning of admission but not just before the onset of chest pain. At 11 a.m. she developed a severe, continuous, nonradiating, retrosternal chest pain which was still present on admission at 3 p.m. On examination she was in pain but did not look ill, and nothing abnormal was detected apart from bilateral crepitus in the neck and a positive Hamman's sign. Chest radiographs showed air in the subcutaneous tissues of the neck and surrounding the mediastinal contents. Lipiodol swallow showed a normal oesophageal outline. The subcutaneous emphysema spontaneously subsided after five days, and a further radiograph taken 12 days after admission was normal.

The diagnosis lay between spontaneous rupture of the oesophagus and sponraneous mediastinal $\overrightarrow{\vec{\rho}}$ emphysema. Oesophageal rupture was unlikely, vomiting did not develop immediately before the onset of retrosternal chest pain, and there was no evidence of shock when the patient was admitted four hours later. The chest radiograph by this time would have $\mathbb{Q}$ shown a pleural effusion if the oesophagus had ruptured.

Compton and Bazin (1957) recorded a case of sub- $\vec{\circ}$ cutaneous emphysema in early pregnancy. They found $\vec{\overrightarrow{ }}$ that only two others had been reported in the $\vec{\sigma}$ literature (Winans, 1947 ; Hovick and West, 1954). Unfortunately no mention was made of mediastinal $x$ emphysema, but presumably this was also present. N Vinson (1932) described a rupture of a benign stric- $\vec{A}$ ture of the oesophagus during vomiting of pregnancy, $\dot{\omega}$ and we have found no record of spontaneous rupture $\mathcal{G}$ following hyperemesis; this is surprising since vomit- 음 ing and oesophagitis are so common throughout pregnancy.

CASE 6 A 23-year-old primigravida was admitted in labour at full term. A chest radiograph taken two 8 months previously was normal. Labour and delivery proceeded normally but the placenta failed to separate and was removed manually under general anaesthesia. Following its removal, she became shocked after losing $1 \mathrm{l}$. of blood and retched and vomited considerably. She was noted to have an: irritable cough; the chest was clinically clear. Seven. hours post-operatively she complained of an aching. retrosternal chest pain, which was inconstantly related to inspiration. On examination she was dyspnoeic and febrile (temperature $100^{\circ} \mathrm{F}$.) ; there was subcutaneous. emphysema of the neck. The pulse was $100 / \mathrm{min}$.; the blood pressure was normal, and the heart sounds. were distant. Nothing abnormal was detected in the respiratory system apart from generalized broncho-spasm.

Chest radiographs taken seven hours post-operatively showed pneumomediastinum and emphysema in the neck. The patient was given a course of intramuscular penicillin and streptomycin. On the: fourth day post partum Hamman's sign was positive, and by the ninth day nothing abnormal could be detected clinically and the radiographs were normal. The cause of pneumomediastinum in this patient is. difficult to determine: the severe vomiting postoperatively might have been sufficient to rupture a marginal alveolus, or an outlet airway obstruction could have developed during the administration of the anaesthetic, producing alveolar distension and rupture. The latter seems unlikely, since the emphysema was not noted until seven hours post-operatively. The other possibility is a perforation of the pharyngeal mucosa secondary to the passage of an endotracheal tube. In the two patients with this condition described by Barrett and Thomas (1944) the surgical emphysema developed during the administration of the anaesthetic, spread rapidly, and was of extreme severity. 
Spellacy and Prem (1963) described three cases of mediastinal emphysema following labour. These authors noted that rarely was any underlying pulmonary disease found, features developed two to nine-and-a-half hours after delivery, and that the condition usually arose in young, healthy primigravidae who pushed well during the second stage of labour. Gordon (1927) commented that none of these cases had been associated with spontaneous pneumothorax. Spellacy and Prem (1963) noted the incidence of pneumomediastinum during labour to be one in 2,600 deliveries, and Kobak and Abrams (1949) reported one in 2,000 deliveries. The treatment of this condition when recognized is conservative. Kobak and Abrams (1949) recommend an elective low forceps delivery when mediastinal emphysema is detected during labour to prevent straining in the second stage. The prognosis is said to be excellent, although Gordon (1927) reported two deaths. In this case the pneumomediastinum caused no distress and treatment was concentrated on controlling the chest infection.

CASE 7 (McKeown, 1965) A man 50 years old, who had suffered from epigastric discomfort after meals for several years, developed epigastric pain after his evening meal and went to bed feeling sick. His wife suggested that should he vomit he might feel better; he retched violently and immediately experienced a severe lower retrosternal chest pain, described as 'something tearing apart'. He remembered nothing after this incident until he reached the casualty department about half an hour later. On admission he was shocked, deeply cyanosed, orthopnoeic, and just able to give a history. Surgical emphysema was felt in the neck; the jugulovenous pressure was raised to $4 \mathrm{~cm}$. and was non-pulsatile. The blood pressure was $130 / 90 \mathrm{~mm}$. $\mathrm{Hg}$, pulse $90 / \mathrm{min}$., the apex beat was not palpable, the heart sounds were distant, and Hamman's sign was positive. The chest was hyperexpanded, and movements were minimal, the percussion note was hyperresonant, and the breath sounds were diminished in all areas but maximal at the left base posteriorly. The abdomen was rigid and tender, with no rebound, and gut sounds were absent.

In view of the previous history of indigestion it was thought that the most probable diagnosis was spontaneous rupture of the oesophagus. This was confirmed by chest radiography which showed mediastinal and surgical emphysema with opacification at the left costodiaphragmatic angle. There was no subdiaphragmatic collection of gas. Left anterolateral thoracotomy was performed, greenish dark fluid was removed from the left pleural cavity, and a vertical rent 1 in. $(25 \mathrm{~mm}$.) long was found on the left posterior wall of the oesophagus just above the diaphragm. The rent was repaired and drained by a tube connected to an underwater seal. A gastrostomy was performed, and the stomach was emptied. The duodenum was noted to be scarred, and there was no evidence of pyloric obstruction. The patient was given a course of intramuscular penicillin and ampicillin post-operatively. Two weeks post-operatively there was complete resolution of the pneumomediastinum; chest radiography showed residual pleural thickening at the left base. The patient was discharged fit 20 days post-operatively.

The rapid recovery and lack of post-operative complications were due to prompt operative therapy. A good history, in association with subcutaneous emphysema of the neck, Hamman's sign, impaired air entry at the left base of the lung posteriorly, and abdominal wall rigidity with no subdiaphragmatic collection of gas, was sufficient to make a concrete diagnosis. This patient had severe air block $^{1}$ on admission, the chest wall was splinted, and the cardiac output was very poor. It is of interest that after intubation and positive pressure ventilation the cyanosis, raised jugulovenous pressure, and low cardiac output were alleviated.

\section{SUMMARY}

The aetiology, diagnosis, and treatment of pneumomediastinum have been discussed. An attempt has been made at classification based on aetiological factors. Seven cases of mediastinal emphysema have been described.

We wish to thank Mr. H. R. England for permission to publish his obstetric cases. Case 7 was presented at the Royal Society of Medicine in December 1964, and we wish to thank Mr. L. R. de Jode and the Royal Society of Medicine for permission to publish this case.

\section{REFERENCES}

Aisner, M., and Franco, J. E. (1949). Mediastinal emphysema. New Engl. J. Med., 241, 818.

Anderson, R. L. (1952). Rupture of the oesophagus. J. thorac. Surg., 24, 369 .

Barrett, N. R. (1946). Spontaneous perforation of the oesophagus: review of the literature and report of three new cases. Thorax, 1 48.

(1952). In Modern Trends in Gastro-enterology, ed. F. Avery Jones, 1st ed., p. 224. Butterworth, London.

- and Thomas, D. (1944). Massive surgical emphysema during the course of general anaesthesia. Brit. med. J., 2, 692 .

Chamberlain, J. M., and Byerly, W. G. (1957). Rupture of the oesophagus. Amer. J. Surg., 93, 271.

Collins, V. L. (1948). Mediastinal emphysema. Med. J. Aust., 1, 614.

Compton, B. C., and Bazin, F. J. (1957). Subcutaneous emphysema in early pregnancy. Amer. J. Obstet. Gynec., 74, 1141.

Cushing, H. (1932). Peptic ulcers and the interbrain. Surg. Gynec. Obstet., 55, 1.

Fincher, E. F., and Swanson, H. S. (1949). Esophageal rupture complicating craniotomy-symptom complex and proposed surgical plicating craniotomy-symptom
treatment. Ann. Surg., 129, 619.

Fine, J., Hermanson, L., and Frehling, S. (1938). Further clinica experiences with $95 \%$ oxygen for the absorption of air from the body tissues. Ibid., 107, 1.

1Macklin and Macklin (1944) defined air block as a condition arising from interference of air in the lung and mediastinum, producing compression of the pulmonary and mediastinal vessels, and interference with respiration by the splinting action of air on the interstitial tissues of the lung. 
Forbes, G. B., Salmon, G., and Herweg, J. C. (1947). Further observations on post-tracheotomy, mediastinal emphysema, and pneumothorax. J. Pediat, 31, 172.

Gordon, C. A. (1927). Respiratory emphysema in labour. Amer. J. Obstet. Gynec., 14, 633 .

Gordon, I. (1936). Benign spontaneous pneumothorax. Lancet, 2, 178.

Griffith, R. S. (1932). The spontaneous rupture of esophagus. Penn. med. J., 35, 639 .

Hamman, L. (1934). Remarks on the diagnosis of coronary occlusion. Ann. intern. Med., 8, 417.

- (1937). Spontaneous interstitial emphysema of the lungs. Trans. Ass. Amer. Phycns, 52, 311.

- (1939). Spontaneous mediastinal emphysema. Bull. Johns Hopk. Hosp., 64, 1.

- (1945). Mediastinal emphysema. J. Amer. med. Ass., 128, 1.

Hollinshead, W. H. (1962). Textbook of Anatomy, 1st ed., p. 811. Harper and Row, U.S.A.

Hovick, J. H., and West, O. T. (1954). Mediastinal and subcutaneous emphysema in early pregnancy. Obstet. and Gynec., 4, 606.

Kennard, H. W. H. (1950). Rupture of esophagus during childbirth. Brit. med. J., 1, 417.

Kjaergaard, H. (1933). Pneumothorax simplex. Two cases with autopsy findings. Acta med. scand., 80, 93.

Klein, A. (1947). Spontaneous mediastinal emphysema with acute right ventricular strain. Amer. Heart J., 33, 867.

Kobak, A. J., and Abrams, R. H. (1949). Pregnancy complicated by massive subcutaneous emphysema of mediastinal origin (Hamman's syndrome). Amer. J. Obstet. Gynec., 57, 789.

Littmann, D. (1946). Electrocardiographic phenomena associated with spontaneous pneumothorax and mediastinal emphysema. Amer. J. med. Sci., 212, 682.

Mackler, S. A. (1952). Spontaneous rupture of the esophagus: an experimental and clinical study. Surg. Gynec. Obstet., 95, 345.

Macklin, C. C. (1937). Pneumothorax with massive collapse from experimental local over-inflation of the lung substance. Canad. med. Ass. J., 36, 414.
Macklin, M. T., and Macklin, C. C. (1944). Ma'ignant interstitial emphysema of the lungs and mediastinum as an important occult complication in many respiratory diseases and other conditions: an interpretation of the clinicalliterature in the light of laboratory experiment. Medicine (Baltimore), 23, 281.

McKeown, D. R. (for L. R. de Jode)(1965). Spontaneous rupture of the esophagus, with recovery following repair. Proc. roy. Soc. Med., 58, 431 .

Mitchell, R. E., Derbes, V. J., and Akenhead, W. R. (1955). Rupture of the esophagus. Two instances of a hitherto undescribed com plication of status asthmaticus. Ann. Allergy, 13, 15.

Müller, F. (1888). Ueber Emphysem des Mediastinum. Berl. klin. Wschr., 25, 205.

Naclerio, E. A. (1957). The "V sign" in the diagnosis of spontaneous rupture of the esophagus. (An early Roentgen clue.) Amer. J. Surg., 93, 291.

Nicholas, J. N. (1958). Mediastinal emphysema. Brit. J. Anaesth., 30, 63 .

Rubin, E. H., and Rubin, M. (1961). Thoracic Diseases. Saunders, Philadelphia and London.

Scott, J. T. (1957). Mediastinal emphysema and left pneumothorax. Dis. Chest, 32, 421.

Smith, C. C. K., and Tanner, N. C. (1956). The complications of gastroscopy and esophagoscopy. Brit. J. Surg., 43, 396.

Spellacy, W. N., and Prem, K. A. (1963). Subcutaneous emphysema and pregnancy. Report of three cases. Obstet. and Gynec., 22, 521.

Sulavik, S. (1962). Mediastinal crunch (Hamman's sign). GP (Kansas), 26, no. 1, p. 104 .

Vinson, P.P. (1932). Spontaneous perforation of benign stricture of the esophagus. Report of a case. Arch. Otolaryng., 16, 329.

Winans, H. M. (1947). Subcutaneous emphysema in vomiting of pregnancy. Amer. J. Med., 2, 412.

Work, W. P. (1943). Mediastinal emphysema and bilateral simultaneous pneumothorax complicating tracheotomy in an adult. Arch. Otolaryng., 37, 526. 